\title{
Event Unit
}

National Cancer Institute

\section{Source}

National Cancer Institute. Event Unit. NCI Thesaurus. Code C150901.

A unit of measure for the number of happenings at a given place or time. 